\title{
Grand multiparity in rural Cameroon: prevalence and adverse maternal and fetal delivery outcomes
}

\author{
Atem Bethel Ajong ${ }^{1 \dagger}$, Valirie Ndip Agbor ${ }^{2,7^{*}+}$ (D) Larissa Pone Simo ${ }^{3}$, Jean Jacques Noubiap ${ }^{4,5}$ and Tsi Njim $5,6,7$
}

\begin{abstract}
Background: Grand multiparity is a major public health concern especially among developing countries and has been associated with higher risk of adverse maternal and fetal outcomes compared with women of lesser parity. There is a dearth of evidence on this subject in Cameroon, especially in the rural areas. We therefore carried out this study to document the prevalence and maternal and fetal delivery outcomes of grand multiparity in a rural Cameroonian setting.
\end{abstract}

Methods: We conducted a retrospective chart review of delivery records from two health facilities (the Oku District Hospital and Kevu Integrated Health Centre) in the Oku Health District over a period of eight years. Data was entered into and analyzed using Epi-Info version 7.0.8.3. The Chi-squared or Fisher's exact test was used to compare categorical variables. The threshold of statistical significance was set at $5 \%$.

Results: A total of 1755 delivery records met our inclusion criteria. The overall prevalence of grand multiparity was 27.0\%. We found no significant difference in the rate of selected maternal and fetal delivery outcomes between grand multiparous women and those with lesser parity ( $p$-value> 0.05 ). However, grand multiparous women were less likely to develop second-fourth degree perineal tears compared to their counterparts with lesser parity (odds ratio $=0.3,95 \%$ confidence interval $=0.2-0.7, p=0.001$ ).

Conclusion: Our study depicts a high prevalence of grand multiparous delivery in this rural community. With the exception of severe perineal tear, grand multipara and their babies are as likely to develop adverse delivery outcomes as their counterparts with lesser parity. There is also the need to enhance existing government policies on reproductive health in rural areas.

Keywords: Grand multiparity, Delivery outcomes, Rural Cameroon

\section{Background}

Solomon's description of a grand multiparous woman the "dangerous multipara" [1,2], has been confirmed in multiple studies [2-4] in the developing setting. Over the years, varying definitions for grand multiparity have been reported in literature, ranging from women with at least four to at least eight previous deliveries [5]. However in the year 1993, the International Federation of Obstetrics and Gynecology defined a grand multiparous woman as one who has had at least five to nine prior term deliveries,

\footnotetext{
* Correspondence: nvagbor@gmail.com

${ }^{\dagger}$ Atem Bethel Ajong and Valirie Ndip Agbor contributed equally to this work. ${ }^{2}$ Ibal Sub-divisional hospital, Oku, Northwest Region, Cameroon

${ }^{7}$ Health and Human Development Research Group (2HD), Douala, Cameroon Full list of author information is available at the end of the article
}

and this definition has been widely adopted by authors in recent literature [5-8]. Women with 10 or more deliveries were classified as great-grand multipara [4].

Grand multiparity, especially in developing countries, has been associated with adverse maternal outcomes during pregnancy such as increased frequency of antepartum hemorrhage, placenta previa, obesity, diabetes mellitus and hypertension [2, 4, 8-10]. Even though, postpartum hemorrhage, cesarean section and malpresentation have been reported as labor and delivery complications of grand multiparity $[2,9,10]$, available evidence remains inconclusive [4]. Also, grand multiparity has been associated with increased risk of preterm delivery, birth asphyxia, low birthweight and early neonatal demise $[5,8,11]$. Most of these 
studies have concluded on the high risk nature of grand multiparous pregnancies $[3,6,7,9,10,12]$.

Grand multiparity is a major public health concern especially in sub-Saharan Africa. This has been associated with a high rate of unmet contraceptive needs [13, 14], compromised or inadequate antenatal and delivery care [14], and low socio-economic status [2, 15, 16]. Developing countries are disproportionately affected by grand multiparity, with higher prevalence rates of $5.1-18.1 \%$ reported in countries like Nigeria [10]. Limited access to competent health personnel, and poor knowledge on and access to contraception aggravates the situation in rural settings $[9,10,17]$. According to the national Demographic and Health Survey (DHS) report in 2011, the average Cameroonian woman of childbearing age was a grand multipara (average fertility rate of 5.1 children per woman) [14]. This rate was even higher in rural Cameroon (6.4 as against 4.0 children per woman in urban Cameroon). About $21 \%$ of these deliveries occurred with an intergensic spacing below two years [14]. Grand multiparity is therefore a serious public health issue in Cameroon, particularly in rural zones.

An evaluation of the weight of this problem and an understanding of the maternal and fetal outcomes in a rural setting of Cameroon is indispensable as interventions aimed at reducing maternal and neonatal morbi-mortality requires this data. To the best of our knowledge, no study has been conducted to evaluate the prevalence and outcome of grand multiparity in rural Cameroon. Herein, we aimed to assess the prevalence and maternal and fetal delivery outcomes of grand multiparity in a rural Cameroonian setting.

\section{Methods}

\section{Study design, duration and settings}

The methods herein have been detailed in an earlier publication [18], and is part of a series of papers aimed at providing relevant data to reduce mother and child morbidity and mortality in rural Cameroon [18-20]. Briefly, we conducted a retrospective chart review of delivery records from two health facilities (Oku District Hospital and Kevu Health Center) in the Oku Health District (OHD) over a period of 8-years spanning from January 1st, 2009 to December 31st, 2016. The Oku District Hospital was managed by a single doctor, while the Kevu primary health center was managed by a nurse with no training in midwifery. Consequently, all caesarean sections were done at the district hospital. Referral in the health district is usually from the primary health care centers to the district hospital. Administratively, the OHD is located in the Bui Division of the Northwest Region of Cameroon. With an estimated population of 93,000 inhabitants, the aforementioned facilities receive a greater majority of the deliveries in this district.

\section{Participants and data collection}

All singleton delivery records from these two facilities within the study period were targeted for this study. All delivery records lacking vital information like the number of previous deliveries were excluded. In addition, records of deliveries at a term below 28 weeks and birth weights below $1000 \mathrm{~g}$ (as these are considered as the threshold of fetal viability in our context), multiple pregnancies, and records with10 or more prior deliveries (considered as great-grand multipara) were excluded. To minimize bias, records of participants with caesarean section (CS) were excluded from this study. This is because CS was only conducted in one of the two health facilities where delivery records were abstracted. Furthermore, in the facility where CS was conducted, this information was only recorded as from 2014. This was highlighted in an earlier publication [18]. However, there was no association between grand multiparity and caesarean delivery (grand multiparity vs lesser parity: $3(0.63 \%)$ vs $11(0.86 \%)$, odds ratio $(\mathrm{OR})=0.7 ; 95 \%$ confidence interval $[\mathrm{CI}], 0.2-2.7)$ when these records were analyzed separately. Data was collected on sociodemographic and clinical characteristics of each mother-and-neonate pair such as: maternal age, marital status, gravidity, parity, gestational age, mode of delivery, human immunodeficiency virus (HIV) status; and the gender, 5th minute Apgar score and birth weight of their neonates. Adverse maternal outcome parameters like postpartum hemorrhage (PPH), dystocia and secondfourth degree perineal tear were recorded. Neonatal asphyxia, fetal demise and abnormal birth weights (high birthweight $[\mathrm{HBW}]$ and low birthweight $[\mathrm{LBW}]$ ) were the evaluated adverse fetal outcomes.

\section{Statistical analysis}

Data was entered into and analyzed using Epi-Info version 7.0.8.3. Variables were categorized as in Table 1 before analysis. Locally defined cut-off values of $<2600 \mathrm{~g}$ and $>$ $3850 \mathrm{~g}$ were used to define LBW [21] and HBW [22], respectively. Means and medians were calculated for continuous variables while frequencies and their 95\% CI were reported for categorical variables. The P-trend was determined using the Mann-Kendall test. With a threshold of statistical significance set at a $p$-value of 0.05 , The OR and corresponding 95\% CI were determined using the Chi square or Fisher's exact test to establish associations between grand multiparity (independent variable) and selected co-variates (outcome variables).

\section{Results}

Of the 1755 included deliveries, 474 occurred in grand multipara, giving an 8-year prevalence of $27.0 \%$ (95\% $\mathrm{CI}=24.9-29.1$ ), Table 2. The mean age of the women was $33.4 \pm 5.0$ years and $23.2 \pm 4.6$ years among grand and non-grand multiparous women, respectively. The 
Table 1 Definition of operational variables

\begin{tabular}{ll}
\hline Parity & $\begin{array}{l}\text { Grand multiparity: Yes (5-9 prior deliveries) } \\
\text { [4]; No }(\leq 4 \text { prior deliveries) }\end{array}$ \\
\hline Gestational age & 1. Preterm delivery: Delivery from \\
& 28 to 36 weeks of gestation \\
& 2. Term delivery: Delivery from 37 \\
& to 42 weeks of gestation \\
& 3. Post-term delivery: Delivery \\
& above 42 weeks of gestation \\
& Neonatal asphyxia. Yes $(<7)$ versus \\
Apgar score at & No $(\geq 7)$ \\
fifth minute & 1. Low birthweight $\leq 2600 \mathrm{~g}[26]$ \\
Birthweight & 2. Normal birthweight: $2601-3849 \mathrm{~g}$ \\
& 3. High birthweight $\geq 3850[27]$
\end{tabular}

ages of our study participants ranged from 14 to 49 years. We observed a non-significantly decreasing trend in the prevalence of grand multiparous deliveries ( $\mathrm{P}$ trend $=0.46$ ) over the study period, Fig. 1 . Over $90 \%$ of grand multipara in our study were married. Among the
1751 cases with a reported maternal HIV status, 4.5\% were positive, Table 2 .

There was no significant difference in adverse maternal outcomes such as postpartum hemorrhage, dystocia, cesarean section, and premature rupture of membranes, among grand multiparous women compared to their counterparts with a lower parity ( $p$-value $>0.05)$. However, grand multiparous women were less likely to develop second-fourth degree perineal tears compared to women with lesser parity $(\mathrm{OR}=0.3[95 \% \mathrm{CI}=0.2-0.7]$, p-value $=$ 0.001; Table 3). When evaluated for fetal outcomes (HBW and LBW, neonatal asphyxia, stillbirth and pre- and postterm deliveries), there were no statistically significant differences between grand multiparous women and those with lesser parity, Table 4.

\section{Discussion}

We sought to determine the prevalence and adverse maternal and fetal delivery outcomes in our study

Table 2 Sociodemographic and clinical characteristics of the study population, Oku Health District, 2009-2017

\begin{tabular}{|c|c|c|c|}
\hline \multirow[t]{2}{*}{ Variable } & \multicolumn{2}{|l|}{ Grand multiparity } & \multirow{2}{*}{$\begin{array}{l}\text { Total N } \\
(\%)=1755 \\
(100.0 \%)\end{array}$} \\
\hline & Yes, $n=474(27.0 \%)$ & No, $n=1281(73.0 \%)$ & \\
\hline \multicolumn{4}{|l|}{ Maternal age (Years) } \\
\hline Mean (SD) & $33.4(5.0)$ & $23.2(4.6)$ & \\
\hline Median (IQR) & $33.5(30.5-37.5)$ & $23.5(19.0-26.5)$ & \\
\hline \multicolumn{4}{|l|}{ Age group (Years) } \\
\hline$[<20]$ & $0(0.0)$ & $361(28.2)$ & $361(20.6)$ \\
\hline [20 to 29$]$ & $94(19.8)$ & $798(62.3)$ & $892(50.8)$ \\
\hline [30-39] & $328(69.2)$ & $121(9.4)$ & $450(25.6)$ \\
\hline$[\geq 40]$ & $52(11.0)$ & $1(0.1)$ & $53(3.0)$ \\
\hline \multicolumn{4}{|l|}{ Marital status } \\
\hline Single & $39(8.3)$ & $393(30.8)$ & $432(24.7)$ \\
\hline Married & $434(91.7)$ & $882(69.2)$ & $1315(75.3)$ \\
\hline \multicolumn{4}{|c|}{ Maternal HIV status $(n=1752)$} \\
\hline Positive & $19(4.0)$ & $59(4.6)$ & $78(4.5)$ \\
\hline Negative & $454(96.0)$ & $1220(95.4)$ & $1673(95.5)$ \\
\hline \multicolumn{4}{|c|}{ Gestational age $(n=1608)$} \\
\hline Term & $259(59.9)$ & $744(63.3)$ & $1003(62.4)$ \\
\hline Preterm & $153(35.3)$ & $372(31.7)$ & $525(32.6)$ \\
\hline Post term & $21(4.8)$ & $59(5.0)$ & $80(5.0)$ \\
\hline \multicolumn{4}{|l|}{ Birthweight $(n=1725)$} \\
\hline LBW & $47(10.1)$ & $122(9.7)$ & $169(9.8)$ \\
\hline Normal birthweight & $383(82.6)$ & $1071(84.9)$ & $1453(84.3)$ \\
\hline HBW & $34(7.3)$ & $68(5.4)$ & $102(5.9)$ \\
\hline \multicolumn{4}{|l|}{ Gender of neonate } \\
\hline Male & $243(51.5)$ & $641(50.2)$ & $884(50.6)$ \\
\hline Female & $229(48.5)$ & $635(49.8)$ & $864(49.4)$ \\
\hline
\end{tabular}

HIV: Human immunodeficiency virus; N: frequency; SD: standard deviation; IQR: interquartile range; LBW: low birthweight; HBW: high birthweight 


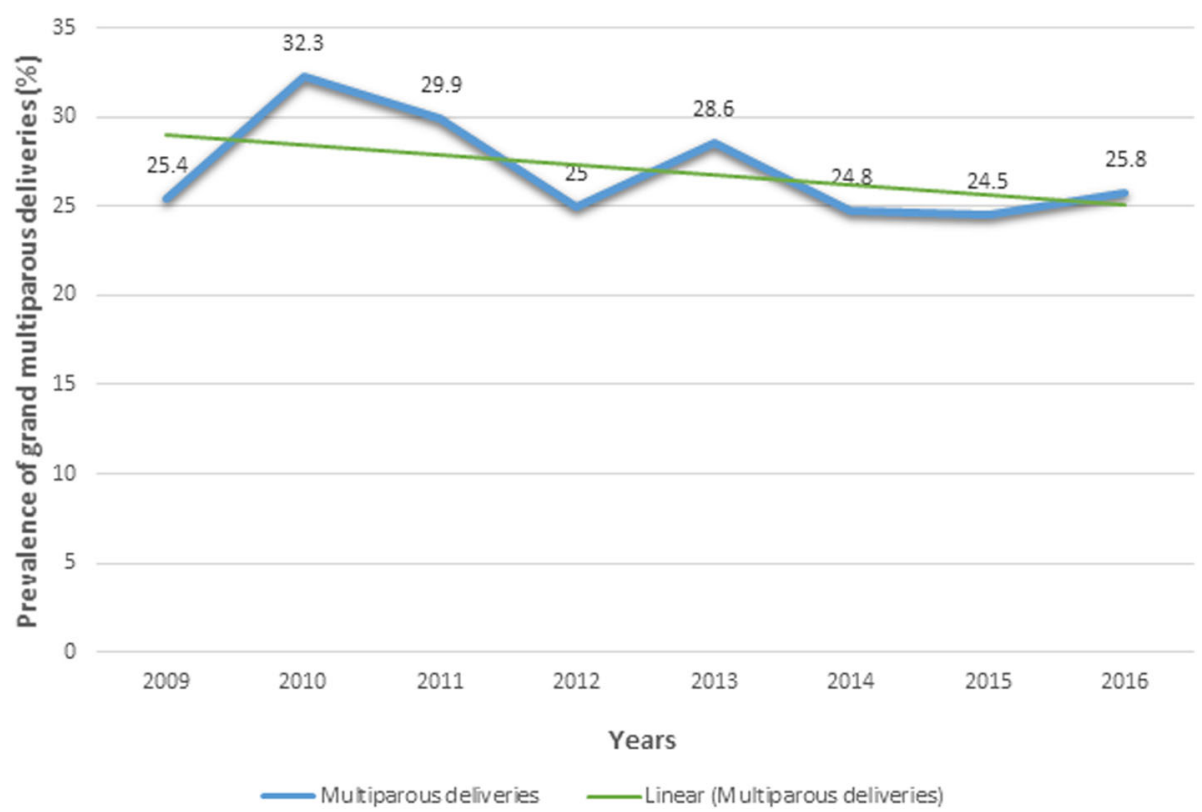

Fig. 1 Trend in the prevalence of grand multiparous deliveries between the years 2009 and 2016 in the Oku Health District $(P$ trend =0.46)

population. Firstly, we observed a very high prevalence of grand multiparity in our study (27\%) with a nonsignificantly decreasing trend between the years 2009 and 2016. Secondly, grand multipara were less likely to develop second - fourth perineal tears than women with a lower parity. No other significant difference in adverse

Table 3 Comparison of maternal outcomes between grand multiparous deliveries and delivery of lesser parity, Oku Health District, 2009-2016

\begin{tabular}{|c|c|c|c|c|}
\hline \multirow[t]{2}{*}{ Outcome } & \multicolumn{2}{|c|}{ Grand multiparity } & \multirow[t]{2}{*}{ OR $(95 \% \mathrm{Cl})$} & \multirow[t]{2}{*}{$p$ - value } \\
\hline & Yes, $n=474$ & No, $n=1281$ & & \\
\hline \multicolumn{5}{|c|}{ Postpartum haemorrhage, $n$ (\%) } \\
\hline Yes & $2(0.4)$ & $5(0.4)$ & $1.1(0.2-5.6)$ & 0.603 \\
\hline No & $472(99.6)$ & $1276(99.6)$ & & \\
\hline \multicolumn{5}{|c|}{ PROM, $n(\%)$} \\
\hline Yes & $5(1.1)$ & $15(1.2)$ & $0.9(0.3-2.5)$ & 0.537 \\
\hline No & $469(98.9)$ & $1266(98.8)$ & & \\
\hline \multicolumn{5}{|c|}{ Caesarean delivery, $n(\%)$} \\
\hline Yes & $3(0.6)$ & $11(0.9)$ & $0.7(0.2-2.7)$ & 0.770 \\
\hline No & $471(99.4)$ & $1270(99.1)$ & & \\
\hline \multicolumn{5}{|c|}{ Dystocia, $n(\%)$} \\
\hline Yes & $2(0.4)$ & $5(0.4)$ & $1.1(0.2-5.6)$ & 0.603 \\
\hline No & $472(99.6)$ & $1276(99.6)$ & & \\
\hline \multicolumn{5}{|c|}{ Second - fourth degree perineal tear, $n(\%)$} \\
\hline Yes & $9(1.9)$ & $68(5.3)$ & $0.3(0.2-0.7)$ & $0.001^{*}$ \\
\hline No & 465 (98.1) & $1213(94.7)$ & & \\
\hline
\end{tabular}

maternofetal delivery outcomes was found among grand multiparous women and those of lower parity.

This high prevalence of grand multiparity is similar to the $26.5 \%$ prevalence rate reported by Idoko et al in a group of pregnant women in Gambia [23]. Also, the investigators of the DHS 2011 highlighted a high prevalence of grand multiparity in rural Cameroon [14]. Indeed, in the Northwest Region of Cameroon where the present study was conducted, the fertility rate in the year 2011 was higher in rural than urban areas (6.4 versus 4.4 children per woman of childbearing age) [14]. This is principally related to the desire for larger family sizes for more labor in farming, mistakes and failed contraception, death of another child, and desire for children of a particular gender [23]. The myth among some rural Cameroonian communities that having more wives and children reflects how wealthy you are, pushes most men in these communities to demand more children from their wives who have little or no control on their sexual and reproductive health. Most of these families find it difficult to train these children through school, or at least supply their basic needs. These children tend to drop out of school and do odd jobs to cater for themselves. Younger girls, majority of whom have a poor knowledge on contraception, will engage in sexual relations with older boys who can provide for them, thereby increasing the rate of sexually transmitted infections, adolescent pregnancies, socioeconomic hardship and poverty. In fact, an earlier study conducted in this rural community revealed a high prevalence of adolescent pregnancy, reflecting on the burden of grand multiparity in this community [18]. Such high prevalence of grand 
Table 4 Comparison of fetal outcomes between grand multiparous deliveries and deliveries of lesser parity, Oku Health District, 2009-2016

\begin{tabular}{|c|c|c|c|c|}
\hline \multirow[t]{2}{*}{ Outcome } & \multirow{2}{*}{$\begin{array}{l}\text { Grand multiparity } \\
\text { Yes, } n=474\end{array}$} & \multicolumn{2}{|l|}{ OR $(95 \% \mathrm{Cl})$} & \multirow[t]{2}{*}{$p$-value } \\
\hline & & No, $n=1281$ & $(73.0 \%)$ & \\
\hline \multicolumn{5}{|l|}{ Birthweight (BW) } \\
\hline Low BW, n (\%) & $47(10.1)$ & $122(9.7)$ & $1.1(0.8-1.5)$ & \multirow[t]{3}{*}{0.712} \\
\hline Normal BW, $n(\%)$ & $383(82.6)$ & $1071(84.9)$ & 1 & \\
\hline High BW, n (\%) & $34(7.3)$ & $68(5.4)$ & $1.4(0.9-2.2)$ & \\
\hline \multicolumn{5}{|c|}{ Neonatal asphyxia (5th min Apgar) } \\
\hline Yes, $n(\%)$ & $9(2.0)$ & $45(3.6)$ & \multirow[t]{2}{*}{$0.5(0.3-1.1)$} & \multirow[t]{2}{*}{0.117} \\
\hline No, $n(\%)$ & $465(98.0)$ & $1236(96.4)$ & & \\
\hline \multicolumn{5}{|l|}{ Stillbirth } \\
\hline Yes, $n(\%)$ & $8(1.7)$ & $15(1.2)$ & $1.4(0.6-3.4)$ & \multirow[t]{2}{*}{0.477} \\
\hline No, $n(\%)$ & $464(98.3)$ & $1264(98.8)$ & & \\
\hline \multicolumn{5}{|l|}{ Term of delivery } \\
\hline Preterm, $n(\%)$ & $153(35.3)$ & $372(31.7)$ & $1.2(0.9-1.5)$ & \multirow[t]{3}{*}{0.163} \\
\hline Term, $n(\%)$ & $259(59.9)$ & $744(63.3)$ & 1 & \\
\hline Post-term, n (\%) & $21(4.8)$ & $59(5.0)$ & $1.0(0.6-1.7)$ & \\
\hline
\end{tabular}

OR: Odd's ratio; $\mathrm{Cl}$ : Confidence interval; $\mathrm{n}$ : frequency

multiparity in rural Cameroon could partly explain why Cameroon failed to attain the objectives of the Millennium Development Goal (MDG) five that was set for the year 2015 [24], and remains a potential threat to the attainment of the sustainable development goal (SDG) three [25] if appropriate measures are not taken to strengthen the application of existing government-based programs on sexual and reproductive health in rural Cameroonian communities. Furthermore, a high prevalence of grand multiparity indirectly prevents the attainment of SDGs 1, 2 and 4 [25].

However, studies conducted in other developing countries like Pakistan, Turkey and Qatar have reported lower than $5 \%$ rates of grand multiparity $[12,17,26]$. The fact that these studies were all carried out in urban zones could explain these low prevalence rates. The cultural, socioeconomic and educational backgrounds of these samples are different from that in rural Cameroon. According to the DHS report in 2011, only $24.1 \%$ of rural Cameroonians had acquired at least a secondary education and up to $44.3 \%$ could neither read nor write.

The rate of second-fourth degree perineal tears was significantly lower in grand multiparous women compared to women of lesser parity. This is probably due to the already extended and flaccid vaginal and perineal muscles due to repeated deliveries. Our result was concordant with those of Eskandar [27] and Riskin-Mashiah [28] where lesser parity was found to be significantly associated with higher risk of severe perineal tears.

Grand multipara were as likely to develop complications such as postpartum hemorrhage, premature rupture of membranes, dystocia, and cesarean section compared to women of lesser parity. A systematic review of grand multiparity in 2006 [4] and a Nigerian survey [29] in 2002 showed that there was no significant difference in postpartum hemorrhage between grand multiparous women and those of lesser parity. Plausible explanations are the multiple training sessions health personnel are submitted to and sensitizations on the application of standard protocols for management of the third stage of labor.

We found no significant difference in adverse fetal outcomes between grand multiparous women and women of lesser parity, Table 4. Even though, there is strong evidence linking abnormal birthweights (HBW and LBW) to increasing parity $[1,3,8,10]$, we found no significant association between abnormal fetal weights and grand multiparity. Our findings corroborated with those of Omole et al [29] who reported no significant difference in abnormal birthweights (LBW and HBW) between grand multiparous women and their counterparts with a lesser parity. Heterogeneity in the definitions of abnormal birthweight used in our study could explain this discrepancy as we used locally generated cutoff values to define LBW and HBW. Also, we found no significant association between neonatal asphyxia, stillbirth and grand multiparity. This finding was similar to those of Alamin et al from Sudan [2]. Other authors have reported no significant association between neonatal asphyxia and increasing parity $[2,3]$. Contrastingly, Yves et al highlighted grand multiparity as a major determinant of neonatal asphyxia and perinatal death [4].

Our study was designed with some limitations, which we believe should be taken into consideration during the global appraisal of the findings presented herein. First, 
the retrospective study design gave us limited control over the quality of data entered into the registers. Nevertheless, we hope the quality of the data used for this study was ameliorated by strict study selection criteria. The low rates of adverse maternal outcomes among the different subgroups is a possible limitation to the statistical power of our analysis. In addition, this study was not designed to evaluate adverse antepartum and postpartum outcomes such as antepartum hemorrhage, placenta previa, eclampsia, obesity, and diabetes mellitus which have been shown to complicate grand multiparous pregnancy $[2,4,9,10]$. Hence, the findings herein are insufficient to disqualify pregnancy in a grand multipara as a high-risk pregnancy. However, these findings resonant with existing literatures disqualifying grand multiparity as a determinant of adverse maternal and fetal outcome during labor and delivery. This study is the first to reveal the prevalence of grand multiparity in rural Cameroon, and with a large sample size, this study provides a contemporaneous picture on the prevalence and outcome of grand multiparity in this rural community.

\section{Conclusion}

About one in four women in this sub-division is a grand multipara. There has been a non-significantly decreasing trend in the prevalence of grand multiparity over an eightyear period. Also, compared to women of lesser parity, grand multipara were less likely to develop perineal tears, and grand multiparity did not increase the odds of adverse maternal and fetal outcomes during delivery. More studies, preferably with a prospective design and large enough sample sizes, are recommended throughout the national territory to validate these preliminary findings and evaluate adverse antenatal and postnatal complications of grand multiparous deliveries in Cameroon. Enhancement of existing government policies on reproductive and sexual health are needed to curb potential socioeconomic burden of grand multiparity in rural areas.

\section{Abbreviations}

Cl: Confidence interval; DHS: Demographic and Health Survey; HBW: High birthweight; LBW: Low birthweight; MDG: Millennium development goal; OHD: Oku District Hospital; OR: Odd's ratio; SDG: Sustainable development goals

\section{Acknowledgements}

The authors will like to thank the staffs of the Oku District Hospital and Kevu Integrated Health Center for their assistance during the study.

\section{Authors' contributions}

Study conception: VNA, and TN; Data collection: VNA; Data analysis and interpretation: VNA and $A B A$; Write up of first manuscript: $A B A$ and VNA; Manuscript revision: ABA, VNA, LPS, JJN and TN. All authors read and approved the final manuscript

\section{Availability of data and materials}

The datasets generated and/or analyzed during the current study are available from the corresponding author on reasonable request.

\section{Ethics approval and consent to participate}

Ethical approval to conduct this study was granted the scientific and ethical review board of the Northwest Regional delegation for Health, Cameroon under the approval number 2016/10/721/NW/RDPH/SP. Authorisations was obtained from the service heads of the Oku District Hospital and the Kevu Integrated Health Center, where this study was conducted.

Consent for publication

Not applicable.

\section{Competing interests}

The authors declare that they have no competing interest.

\section{Author details}

${ }^{1}$ Maternity and Surgical Department, Kekem District Hospital, Kekem, Cameroon. ${ }^{2}$ Ibal Sub-divisional hospital, Oku, Northwest Region, Cameroon. ${ }^{3}$ Faculty of Health Sciences, University of Bamenda, Bamenda, Cameroon. ${ }^{4}$ Department of Medicine, University of Cape Town and Groote Schuur Hospital, Cape Town, South Africa. ${ }^{5}$ Cape Universities Body Imaging Center, University of Cape Town, Cape Town, South Africa. ${ }^{6}$ Nuffield Department of Medicine, University of Oxford, Oxfordshire, UK. ${ }^{7}$ Health and Human Development Research Group (2HD), Douala, Cameroon.

Received: 11 December 2017 Accepted: 24 June 2019

Published online: 05 July 2019

\section{References}

1. Mgaya AH, Massawe SN, Kidanto HL, Mgaya HN. Grand multiparity: is it still a risk in pregnancy? BMC Pregnancy Childbirth. 2013;13:241.

2. Ahmed IAM. Maternal and Fetal Outcome of Grandmultipara in Comparison to Multiparous Woman in Two hospital in Khartoum State. http://www. academia.edu/download/32122016/F0962242.pdf.

3. Rajlaxmi M, Manika A, Singh AS. Obstetrical challenges of grand multiparaexperience from a TERTIARY care Centre. International Journal of Innovative Medicine and Health Science. 2013;1:1-5.

4. Yves J, Katrien V, Sanne V. A systematic review of grand multiparity. Current Women's Health Reviews. 2006;2:25-32.

5. Nasrullah FD, Khan A, Haque S. Grand MULTIPARITY and obstetric complications: a COMPARATIVE study with women of low parity in a TERTIARY care hospital. Medical Channel 2016;22. https://pdfs. semanticscholar.org/0739/ec573306c0d9ad77481f4830efb282baecdc.pdf.

6. Rizwan N, Parveen G, Abbasi RM. Frequency of grand multiparity and its fetomaternal outcome at Liaquat University hospital, Hyderabad. ISRA MEDICAL JOURNAL. 2009:49

7. Severinski NS, Mamula O, Severinski S, Mamula M. Maternal and fetal outcomes in grand multiparous women. Int J Gynecol Obstet. 2009;107:63-4.

8. Al-Shaikh GK, Ibrahim GH, Fayed AA, Al-Mandeel H. Grand multiparity and the possible risk of adverse maternal and neonatal outcomes: a dilemma to be deciphered. BMC Pregnancy and Childbirth. 2017;17. https://doi.org/10. 1186/s12884-017-1508-0.

9. Alsammani MA, Ahmed SR. Grand multiparity: risk factors and outcome in a Tertiary hospital: a Comparative study. Mater Sociomed. 2015;27:244-7.

10. Afolabi AF, Adeyemi AS. Grand-multiparity: is it still an obstetric risk? Open Journal of Obstetrics and Gynecology. 2013;03:411-5.

11. Samueloff A, Mor-Yosef S, Seidman D, Rabinowitz R, Simon A, Schenker J. Grand multiparity: a nationwide survey. Isr J Med Sci. 25:625-9.

12. Meena S, Kabra A, Sehra D. A CLINICAL STUDY TO ASSESS THE MATERNAL AND FOETAL OUTCOME IN GRANDMULTIPARA. Hypertension. 25:12-5.

13. Ajong AB, Njotang PN, Yakum MN, Essi MJ, Essiben F, Eko FE, et al. Determinants of unmet need for family planning among women in urban Cameroon: a cross sectional survey in the Biyem-Assi Health District. Yaoundé BMC Women's Health. 2016;16:4.

14. Institut National de la Statistique/Cameroun IN de la Sante, International ICF. Cameroun Enquête Démographique et de Santé et à Indicateurs Multiples (EDS-MICS) 2011. 2012. http://dhsprogram.com/publications/publicationfr260-dhs-final-reports.cfm. 
15. Qamar A, Asif U, Qamar S. Maternal and fetal outcome in grand multipara. Pakistan Armed Forces Medical Journal. 2015;65:135-40.

16. Tolefac PN, Halle-Ekane GE, Agbor VN, Sama CB, Ngwasiri C, Tebeu PM. Why do pregnant women present late for their first antenatal care consultation in Cameroon? matern health, neonatol and perinatol. 2017;3:29.

17. Bezircioğlu I. The effect of grandmultiparity on maternal, obstetric, fetal and neonatal outcomes. Perinatal Journal. 2013;21:17-22.

18. Agbor VN, Mbanga CM, Njim T. Adolescent deliveries in rural Cameroon: an 8-year trend, prevalence and adverse maternofoetal outcomes. Reprod Health. 2017;14:122.

19. Njim T, Agbor VN. Adolescent deliveries in rural Cameroon: comparison of delivery outcomes between primipara and multipara adolescents. BMC Res Notes. 2018;1::427.

20. Agbor VN, Ditah C, Tochie JN, Njim T. Low birthweight in rural Cameroon: an analysis of a cut-off value. BMC Pregnancy Childbirth. 2018;18:30.

21. Njim T, Atashili J, Mbu R, Choukem S-P. Low birth weight in a sub-urban area of Cameroon: an analysis of the clinical cut-off, incidence, predictors and complications. BMC Pregnancy Childbirth. 2015;15. https://doi.org/10. 1186/s12884-015-0723-9.

22. Choukem S-P, Njim T, Atashili J, Hamilton-Shield JP, Mbu R. High birth weight in a suburban hospital in Cameroon: an analysis of the clinical cut-off, prevalence, predictors and adverse outcomes. BMJ Open. 2016;6:e011517.

23. Idoko P, Nkeng G, Anyawu M. Reasons for current pregnancy amongst grand multiparous Gambian women - a cross sectional survey. BMC Pregnancy Childbirth. 2016;16:217.

24. MDG Reports Cameroon_FINAL_1.pdf. http://www. commonwealthfoundation.com/sites/cwf/files/downloads/ MDG\%20Reports\%20Cameroon_FINAL_1.pdf. Accessed 4 Jan 2017.

25. Transforming our world: the 2030 Agenda for Sustainable Development ... Sustainable development knowledge platform. https:/sustainabledevelopment. un.org/post2015/transformingourworld. Accessed 23 Apr 2017.

26. Ahmed Bl, Kenyab N, Saleh N, Azzam A, Almohandi H. Pregnancy outcome in grand and great grand multiparity. Qatar Medical Journal. 2005;2005:12.

27. Eskandar O, Shet D. Risk factors for 3rd and 4th degree perineal tear. J Obstet Gynaecol. 2009;29:119-22.

28. Riskin-Mashiah S, O'Brian Smith E, Wilkins IA. Risk factors for severe perineal tear: can we do better? Am J Perinatol. 2002:19:225-34

29. Omole-Ohonsi A, Ashimi AO. Grand multiparity: obstetric performance in Aminu Kano teaching hospital, Kano, Nigeria. Niger J Clin Pract. 2011;14:6.

\section{Publisher's Note}

Springer Nature remains neutral with regard to jurisdictional claims in published maps and institutional affiliations.

Ready to submit your research? Choose BMC and benefit from:

- fast, convenient online submission

- thorough peer review by experienced researchers in your field

- rapid publication on acceptance

- support for research data, including large and complex data types

- gold Open Access which fosters wider collaboration and increased citations

- maximum visibility for your research: over $100 \mathrm{M}$ website views per year

At BMC, research is always in progress.

Learn more biomedcentral.com/submissions 